\title{
O AUtor, O TrAdutor SEMPRE Visível E O PODER SimbÓLICO
}

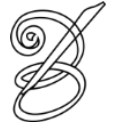 \\ Alessandra Matias Querido \\ (Pós-doutoranda - UFSC-Florianópolis/Brasil) \\ alequerido@gmail.com
}

\begin{abstract}
Resumo: Uma das discussões teóricas nos Estudos de Tradução diz respeito à visibilidade/invisibilidade do tradutor e à fidelidade ao texto-fonte. Acreditamos que o tradutor está sempre visível no texto por suas diversas escolhas e que a discussão sobre a visibilidade deveria extrapolar os limites textuais, tendo em vista que a questão refere-se a aspectos sociais que legitimam ou não o trabalho do autor e do tradutor, ou o poder simbólico dado a cada um deles na sociedade.
\end{abstract}

Palavras-chave: tradutor, visibilidade, autor, poder simbólico.

Abstract: One of the most debated issues on Translation Studies is about the translator's visibility/invisibility and about faithfulness to the source text. We believe that the translator is always visible in the text due to his/her choices. Therefore, the discussion about visibility should overcome textual issues since there are social aspects that must be considered and that legitimate or not author's and translator's work, or the symbolic power each part have inside society.

Keywords: translator, visibility, author, symbolic power.

“... apenas recentemente o tradutor - como Constance Garnett, C.K. Scott Moncrieff, Arthur Waley - começou a emergir de uma posição obscura de servidão indistinta. E mesmo aqui, sua visibilidade é frequentemente aquela de um alvo."

George Steiner

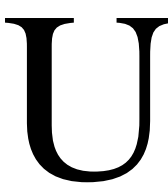
ma das discussões mais acirradas nos Estudos de Tradução talvez seja a que diz respeito à tradução e autoria. Há vários debates que ressaltam o papel do tradutor como coautor do texto e, por isso, ele também deveria ser visível aos olhos do leitor. Em contraposição, há autores (e tradutores também) que pregam a invisibilidade, a ideia de o texto ser uma emanação do autor/criador que deve permanecer inalterada e pura, sem a interferência do tradutor.

Preso a esse último discurso, o tradutor tenta ser "imagem e semelhança" do autor e oscila entre a suposta invisibilidade que os leitores anseiam e a constatação de que é impossível não aparecer no texto, mostrar sua paixão. O tradutor, principalmente o literário, é 
tido como aquele que de alguma forma corrompe a originalidade do autor. O clássico “tradutor, traidor" ilustra a má reputação a ele imposta.

Enquanto "a propriedade das obras não era em primeiro lugar a do próprio autor, nem a originalidade o primeiro critério a comandar a sua composição ou apreciação" (CHARTIER, 2010, p. 18), o tradutor não era visto assim. Como ressalta Bassnet, houve uma alteração de status:

Embora no princípio do século XIX a tradução ainda fosse encarada como um método sério e útil de ajudar um escritor a explorar e a moldar seu estilo natural, essa época também testemunhou uma viragem no estatuto do tradutor, com o trabalho de um número crescente de tradutores "amadores" (entre os quais muitos diplomatas ingleses), para quem o objectivo das traduções tinha mais que ver com a divulgação dos conteúdos de uma determinada obra do que com a exploração das propriedades formais do texto. A transformação ao nível dos conceitos de nacionalismo e de língua nacional agudizou as barreiras interculturais e o tradutor acabou gradualmente por ser visto, não como um artista criador, mas como um elemento na relação de senhor-servo que mantém com o texto da LP (BASSNET, 2003, p. 22).

É válido ressaltar que essa viragem de estatuto, citada por Bassnet (2003), diz respeito

ao fato de os tradutores terem, por determinado tempo, recebido muito crédito por seu trabalho, sendo inclusive os responsáveis pela compra e divulgação de obras literárias e, posteriormente, foram relegados ao segundo plano. Cervantes (2007, p. 736), em Dom Quixote, fala que o tradutor relata não precisar imprimir livros para adquirir renome mundial (tendo em vista que renome já tem), mas para ter lucro, sem o qual, de nada vale a boa fama.

\begin{abstract}
A oposição entre fama e provecho, renome e lucro é um lugar-comum na Espanha do Século de Ouro. Mas aqui vem associada a uma percepção aguda do mundo literário. Os tradutores são, de fato, os primeiros "autores" a receber pelo seu manuscrito, não somente exemplares de sua obra destinados a ser oferecidos a seus protetores, mas também uma remuneração monetária. Há uma primeira etapa da profissionalização do trabalho de escrita ligada a uma atividade aparentada com a cópia. Aliás, a mesma palavra trasladar designa, no castelhano do século XVII, as duas atividades, copiar e traduzir, assim como indica a definição de Covarrubias. Preocupado em ganhar dinheiro com seu livro, o tradutor não pretende ceder seu privilégio a um livreiro que obteria todo o lucro com o eventual sucesso da obra (CHARTIER, 2010, p. 105).

Na Europa renascentista, a tradução desempenhou um papel de importância central. [...] A tradução não foi, de modo nenhum, uma actividade secundária; foi antes uma actividade primária, exercendo poder modelador da vida intelectual da época e, por vezes, a figura do tradutor parece quase mais a do activista revolucionário do que a do servo de um autor ou texto original (BASSNET, 2003, p. 102-103).
\end{abstract}

De negociante dos valores a serem pagos pelo texto traduzido (tendo lucro com isso), responsável pelo intercâmbio de conhecimento e ativista, o tradutor passou a ser visto como servo dos autores. A partir do momento em que foi estabelecida a "paternidade" dos textos, o 
papel do tradutor passou a ser subestimado. Partiu-se da ideia de que "em arte, ninguém mais do que o autor está na própria casa" (COMELLAS, 2009, p. 11). Por essa razão, o tradutor foi, e ainda o é, alvo de críticas de alguns autores que se sentem injustiçados e leitores ou críticos literários indignados com a pretensa perda da originalidade das obras.

O autor Nabokov, por exemplo, via a tradução como um ato criminoso e fútil e tinha o hábito de dizer que as traduções alheias eram um horror. Depois de traduzir "Eugene Onegin" para o inglês, Nabokov divulgou um poema que era um tributo ao trabalho de Pushkin e um pedido de desculpas aos russos e ao autor. O poema ${ }^{1}$ expressa a ideia de Nabokov (apud REMNICK, 2005, p. 104-105) acerca da tradução:

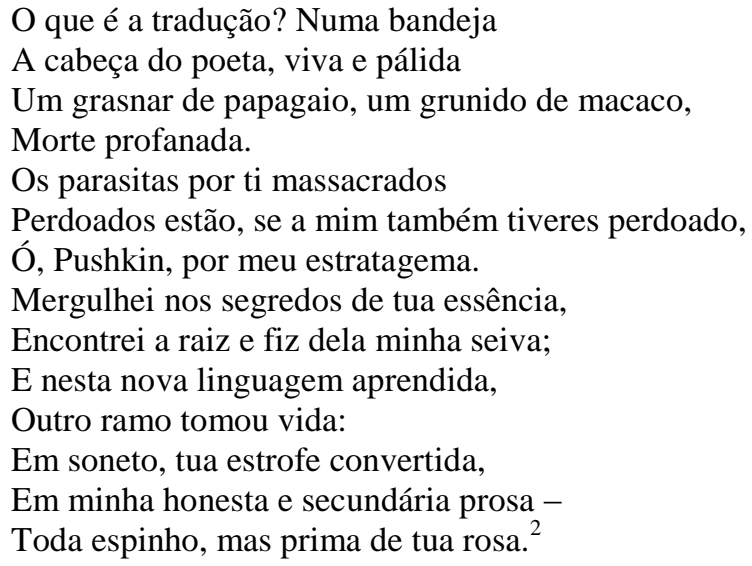

A tradução aparece como texto secundário e "toda espinho", como o grasnar de um papagaio ou o grunhido do macaco e mais: como profanação dos mortos. Para a maioria das culturas, a profanação é um crime gravíssimo, e quanto à tradução, a metáfora implica que o tradutor mexe no que não deveria: o que é sagrado. Nabokov faz eco para Du Bellay (2004, p. 29) quando este, ao falar sobre a tradução de poemas, dizia: "Oh Apolo! Oh Musas! Profanar desta maneira as relíquias da Antiguidade!”

Milan Kundera também partilha do ponto de vista de que o tradutor não é bem-vindo; para ele, "se uma obra de arte é a emanação de um indivíduo e de sua unicidade, é lógico que este ser único, o autor, possua todos os direitos sobre aquilo que é a emanação exclusiva dele próprio" (KUNDERA, 1993, p. 249). De acordo com ele, "a autoridade suprema para um tradutor deveria ser o estilo pessoal do autor" (KUNDERA, 2009, p. 99). Kundera dizia que os tradutores obedeciam apenas à autoridade do estilo comum da língua aprendida no colégio. A afirmação do escritor nos leva à ideia de que nenhuma tradução poderia ter o nível que ele considerava adequado aos seus textos; todas apresentavam uma versão simplista, medíocre, 
do que era a sua obra de arte. A ideia remete a Du Bellay, o qual, em 1549, pensava de maneira semelhante.

Mas o que diria daqueles realmente mais dignos de serem chamados traidores do que tradutores? Porque traem aqueles que eles se propõem expor ao público, tirando deles a glória, do mesmo modo eles enganam os leitores ignorantes, mostrando-lhes o branco onde há preto; que, para passar por sábios, traduzem levianamente de línguas das quais não entenderam nem o básico, como o hebraico e o grego. E para aparecer ainda mais, escolhem os poetas, gênero de autores que eu, se soubesse ou quisesse traduzir, sem dúvida não escolheria, por causa daquela invenção divina que eles têm mais do que os outros, daquela grandeza de estilo, nobreza nas palavras, gravidade nas sentenças, audácia e variedade de figuras, e mil outras luzes de poesia: em resumo, aquela energia e não sei que espírito, que está em seus escritos, e que os Latinos chamavam de genius (DU BELLAY, 2004, p. 29).

Para os autores supracitados, talvez fosse melhor que a tradução sequer existisse. $\mathrm{Na}$ impossibilidade de evitá-la, que o tradutor fosse então capaz de transmitir a obra sem interferir, invisível e fiel. Sobre essa noção de fidelidade, além de autores e leitores que almejaram ou almejam essa postura do tradutor, também a própria Teoria da Tradução teve sua participação na construção dessa visão do tradutor "ideal" e invisível, uma vez que, ao fixar noções logocêntricas acerca do processo tradutório, acabou reiterando a sacralidade dos 108 textos e a posição subalterna do tradutor.

A noção do tradutor ideal, baseada na noção linguística sistêmica do falante ideal e no construto logocêntrico do "original sagrado" e descontextualizado, fez com que a tradução fosse vista como uma cópia também descontextualizada e relegou os tradutores à invisibilidade, reduzindo seu status a transcodificadores e máquinas de tradução (PRUNC, 2007, p. 40).

O tradutor é considerado perfeito quando não é detectado no texto traduzido, quando ele é supostamente fiel, como se isso fosse possível. Como explica Meschonnic, "quanto mais o tradutor se inscreve como sujeito na tradução, mais, paradoxalmente, traduzir pode continuar o texto" (MESCHONNIC, 2010, p. xxxiv).

Exigir fidelidade a uma tradução literária não faz parte do espírito que é o fundamento do indivíduo, e sim do espírito que é o fundamento do feudalismo e do patriarcado. Em troca, aceitar que a própria obra, sem deixar de ser o produto de uma conjunção única, é uma reescrita e pode e deve ser reescrita por outra individualidade que ao fazê-lo vai renová-la, vai iluminá-la de outro ângulo ou vai situá-la noutro nó da rede, é fazer possível a continuidade da ideia de indivíduo numa comunidade de pessoas livres, talvez com divisão do trabalho, mas sem hierarquias. A literatura não é um filme de milhões de reais, com uns produtores que provavelmente não sejam senão uma entidade financeira sem rosto - com rostos intercambiáveis, sem indivíduos. Atendendo a que, na literatura, ninguém é dono de nada mais além da caneta ou do computador (COMELLAS, 2009, p. 26).

Arrojo argumenta que essa noção de fidelidade ao autor pressupõe que apenas o textofonte pode ser original porque traz a representação pura do que o autor expressou, e a 
tradução passa a ser um texto de segunda ordem. Ao ressaltar que para Freud a criação literária tem relação íntima com o desejo de dominar o real e moldá-lo, como se fosse um texto que deve obedecer aos caprichos do criador e soberano, e que, para Nietzsche, a noção de criação tem a ver com a noção do "desejo de potência" ou com "o impulso criador e procriador da vida", ela explica que é

\begin{abstract}
possível compreender de uma forma mais abrangente, por exemplo, a noção tão amplamente difundida segundo a qual a tradução e aqueles que a ela se dedicam devem se manter absolutamente invisíveis e subservientes à obra e às intenções do Autor, como se essa fosse uma opção possível ou atingível. Afinal, no texto criado pelo Autor, que emergeria de seu desejo de ser invulnerável ao desejo autoral do outro, ou, como poderíamos argumentar a partir de Nietzsche, de seu "desejo de potência", não deve haver lugar para a "criatividade" do leitor, ou qualquer versão da "visibilidade" do tradutor, vistos como forasteiros que, sobretudo conscientemente, poderiam acabar usando o texto alheio como tela para a projeção de seu próprio desejo de potência (ARROJO, 2003, p.196).
\end{abstract}

Comellas argumenta de forma semelhante a Arrojo ao questionar com ironia a ideia de Milan Kundera de que "a casa pertence apenas ao autor":

\begin{abstract}
Incompreensão, egocentrismo, academicismo... Ou a tradução pensa demais em si mesma (e quem traduz quer deixar nela um cunho pessoal) ou pensa demais no leitor (na fisionomia da língua de chegada, no "grande estilo"), mas nunca pensa o suficiente no autor. Tradutoras, tradutores, vocês não estão na vossa casa! Não podem mudar a cor das paredes ou a orientação da luz, embora, talvez nesse ponto, a vossa língua não use a mesma cor, ou o sol seja menos forte. Se o que pretendem é mudar tudo, construam a vossa própria casa (KUNDERA, 2009, p. 15).
\end{abstract}

Quanto à invisibilidade, Venuti (1995, p. 5) afirma que, sob o regime da tradução fluente, o tradutor se esforça para tornar seu trabalho invisível, mascarando seu status na ilusão de que o texto traduzido seja natural, ou melhor, que não pareça uma tradução. $\mathrm{O}$ teórico (VENUTI, 1995, p. 6) ainda afirma que essa invisibilidade é, em parte, determinada pela concepção que se tem de autor, o qual expressa suas ideias e sentimentos em um processo de autorrepresentação transparente e original.

Venuti argumenta que uma tradução domesticada faz com que o tradutor fique invisível no texto. Contudo, podemos questionar se é realmente por "domesticar" o texto que o tradutor se torna invisível, afinal, em cada escolha vocabular, em cada caminho de interpretação, o tradutor se mostra. Sendo assim, talvez fosse mais pertinente dizer que a invisibilidade do tradutor não se dá dentro do texto (porque ali, independentemente de seu querer ou da estratégia de tradução escolhida, ele pode ser notado), mas no âmbito social, no sentido de o tradutor não ter o seu trabalho reconhecido. 


\begin{abstract}
A luta [pela visibilidade] me parece mais frutífera se for realizada num campo que o próprio Venuti chama de "contexto externo", ou seja, as instituições acadêmicas, as editoras etc. Quanto mais se falar e escrever sobre tradução, mais os tradutores serão ouvidos [...]. Se todo texto é um espaço "multidimensional, onde vários significados possíveis se combinam e se contrapõem", quem garante que as tais marcas serão realmente percebidas pelo leitor? (ESTEVES, 1993, p. 4).
\end{abstract}

O problema é: ao contrário do que acontece com o escritor, o qual tem respaldo de vários agentes (editores, críticos literários, leitores, etc.) para corroborar a legitimidade do seu trabalho, o tradutor não tem o mesmo suporte. Um motivo claro é o fato de as pessoas não esperarem uma "interferência" entre elas e o texto escolhido para ler, ou seja, as pessoas partem do pressuposto de que, ao escolherem um livro, estão lendo-o como se tivesse saído diretamente do pensamento e dos dedos do autor como obra de arte irretocável. Parte desse desejo talvez se dê pela illusio (BOURDIEU, 2009, p. 286) proposta por Bourdieu, isto é, o jogo que se estabelece dentro do campo artístico, o círculo da crença da atitude estética. É a ideia de "criação original", o discurso que contribui para considerar o texto como produção particular e que dá condições “da criação social do 'criador' como fetiche” (BOURDIEU, 1996, p. 264).

110 A vontade de encontrar apenas o escritor no texto se dá pelo "prazer do culto" (BOURDIEU, 2008, p. 460) ou pelas referências que legitimam o texto enquanto obra de arte, digna de valoração, de poder simbólico, “esse poder invisível o qual só pode ser exercido com a cumplicidade daqueles que não querem saber que lhe estão sujeitos ou mesmo que o exercem" (BOURDIEU, 2009, p. 7-8). De acordo com o autor, o campo literário é um campo social separado, com suas próprias leis de funcionamento. Para o sociólogo, a existência dos escritores como fato e valor é inseparável da existência do próprio campo literário como universo autônomo com princípios específicos de funcionamento.

\footnotetext{
Para entender Flaubert ou Baudelaire, ou qualquer autor maior ou menor, primeiro é necessário entender no que consiste o status do autor num dado momento; isto é, mais precisamente as condições sociais que possibilitam a função social deste personagem social. De fato, a invenção dos escritores no sentido moderno do termo é inseparável da invenção progressiva de um jogo social particular, ao qual denomino campo literário, constituído à medida que estabelece sua autonomia, ou seja, suas leis específicas de funcionamento dentro de um campo de força (BOURDIEU, 1993, p. 162-163).
}

O escritor, enquanto personagem social, ao ter sua obra legitimada como arte, adquire poder simbólico que tende a ser reiterado. O que ocorre com o autor legitimado é que seu nome e sua assinatura passam a ter atribuição quase "sagrada". Esse poder simbólico também o acompanha quando ele traduz, pois muitos leitores buscam na tradução realizada por autores 
consagrados a mesma legitimidade que encontram em seus textos originais, isto é, quando um autor consagrado traduz, ele "empresta" à obra traduzida parte do seu poder simbólico.

O tradutor, mesmo que não seja autor de seus próprios livros, também adquire legitimação do seu trabalho quando traduz autores consagrados. Nesse caso, é o tradutor que corrobora com a ratificação do poder simbólico do autor que é apresentando à outra cultura; é ele quem leva ao conhecimento do público o novo texto e o nome do autor.

Pela tradução, o tradutor exerce o papel do agente que confere ao autor e a seu trabalho uma quantidade de capital, submetendo-os à lógica do campo literário da língua alvo e a seus mecanismos de reconhecimento (GOUANVIC, 2005, p. 162).

Ainda que o tradutor atue como agente do autor, para o senso comum o escritor é aquele a quem foi dado o título de criador e, embora muito tenha mudado com relação à sua posição na Teoria Literária, tendo sido decretada até sua morte por Barthes, ele ainda ocupa lugar privilegiado. De fato, a morte do autor trouxe consigo a morte do texto original (BASSNET, 1996, p. 3), o que significa que a tradução não mais poderia ser considerada um texto de segunda ordem e o tradutor não mais o traidor. Na verdade, longe de ser um texto secundário, a tradução seria a continuação da vida do texto, como propôs Derrida ao afirmar que o texto só vive se ele sobrevive sendo traduzido.

A partir do momento em que, na Teoria Literária, o autor passou a não ser visto como o dono absoluto da casa ou das verdades do texto, foi dado um passo em direção à plurissignificação das narrativas, à diversidade de leituras. O texto tornou-se um "mar aberto" (BURKE, 1998, p. 24), não mais envolto em cores de caráter eterno e imutável. Evidentemente, esse "mar aberto" não implica qualquer tipo de leitura e interpretação, mas na possibilidade de o processo ser influenciado por fatores que podem mudar de acordo com o contexto em que se traduz.

Recentemente, no campo dos estudos de tradução, os pesquisadores pararam de acreditar que é possível alcançar a interpretação de um texto e perceberam que textos são obras abertas, o sentido é construído de acordo com nossas crenças e contextos e não há o texto em si, mas um intertexto composto de múltiplas vozes. Esse ponto de vista, impensável em perspectivas mais tradicionais e conservadoras, estabelece que os autores não são mais os únicos detentores do sentido verdadeiro de seu discurso e que os leitores e tradutores são coautores. (VIDAL CLARAMONTE, 2005, p. 262).

A proposta de Barthes era desmistificar a figura do autor; não obstante, Burke (BURKE, 1998, p. 17) argumenta que a morte do autor soa como uma afirmação não muito séria para o senso comum, sendo, no máximo, considerada outro conceito de vanguarda. 
Como da morte de Deus, da morte do autor apenas souberam, de fato, umas poucas pessoas. E da mesma forma que, ao longo da história, algumas dessas pessoas que pensaram ter visto a morte de Deus decidiram silenciá-la (para conservar os privilégios, como Voltaire, ou para não tirar um consolo aos que não têm mais nada, como Unamuno), também a maior parte da crítica artística se recusou a enterrar a autoria (COMELLAS, 2009, p. 18).

Isso significa que o poder simbólico do autor ainda se mostra presente, principalmente no universo da tradução. Wolf (2007, p. 139) explica que os instrumentos de consagração ou legitimação do trabalho do tradutor são bem menos estabelecidos do que aqueles que dizem respeito à originalidade dos escritores e de suas obras. "O que faz o poder das palavras é a crença na legitimidade das palavras daquele que as pronuncia, crença cuja produção não é de competência das palavras" (BOURDIEU, 1993, p. 15).

Dessa forma, a ideia de que apenas o autor detém a legitimidade da palavra depende também de fatores externos a ele, fatores sociais que permitem e corroboram a noção do autor como dono e senhor de sua obra. Para muitos,

o autor é para o texto o que Deus, o auctor vitae, é para o mundo: a causa unitária, a fonte e o senhor para o qual a cadeia dos efeitos do texto converge e no qual se encontra sua gênese, significado, propósito e justificativa. (BURKE, 1998, p. 23)

Em As regras da arte, Pierre Bourdieu aborda alguns tópicos que poderiam estar no cerne da visão que se tem do tradutor, e cita Flaubert, o qual explica que o autor viria a ser aquele capaz "de se pôr de um salto acima da humanidade e de nada ter com ela em comum, a não ser uma relação do olhar" (FLAUBERT apud BOURDIEU, 1996, p. 49). No papel de "observador puro" (BOURDIEU, 1996), o autor teria atributos divinos de eternidade e ubiquidade. Além disso, o escritor trabalharia por "amor à Arte", idealista de que seu trabalho teria valor incalculável, conceito corroborado por aqueles que classificam a obra literária como arte. Os modos de produção cultural seriam a "arte pura" e a "arte comercial" (BOURDIEU, 1996, p. 197). Nesse cenário, possivelmente, para o senso comum, o tradutor seria encaixado na categoria da "arte comercial" (à exceção dos tradutores já consagrados), porque, em teoria, não trabalharia por amor à Arte (já que esse privilégio é prerrogativa do autor), mas por razões puramente comerciais.

O produtor do valor da obra de arte não é o artista mas o campo de produção enquanto universo de crença que produz o valor da obra de arte como fetiche produzindo a crença no poder criador do artista. Dado que a obra de arte não existe enquanto objecto simbólico dotado de valor a menos de ser conhecida e reconhecida, ou seja, socialmente instituída como obra de arte por espectadores dotados da disposição e da competência estéticas que são necessárias para a conhecer e a reconhecer como tal, a ciência das obras tem por objecto não só a 
produção material da obra mas também a produção do valor da obra ou, o que vem a dar no mesmo, da crença do valor da obra (BOURDIEU, 1996, p. 261-262)

Se legitimamos a atribuição de valor à obra de arte, reafirmando a crença no poder criador do artista, estamos reiterando a ideia da obra de arte como fetiche, numa tentativa de fixar o significado e protegê-lo, evitando qualquer interferência externa, principalmente do tradutor que poderia "profaná-la", parodiando as palavras de Nabokov.

Entretanto, como já percebido, proteger o que já não mais pertence ao autor, pois que a obra de arte só reencontra seu sentido em novas leituras, é uma tarefa impossível: "define-se a meta da tradução com base numa ética que prega a proteção cega e incondicional do desejo e dos significados do autor, sem que se questione, por exemplo, se esse tipo de proteção seria viável ou não" (ARROJO, 2003, p. 196). Partindo do princípio de que nenhuma leitura de um texto será igual, e "sempre a apropriação é criadora, produção de uma diferença, proposta de um sentido possível" (CHARTIER, 2010, p. 25), percebemos a inviabilidade do que se espera da tradução e do tradutor.

\begin{abstract}
O tradutor literário trabalha com um texto escrito por outra pessoa e transforma-o escrevendo em outra língua. Esta afirmação simples esconde um processo complexo de transformação imaginativa que se mantém em profundo diálogo com o texto fonte. O tradutor lê, relê, escreve, refaz o rascunho, autoedita, reescreve. Durante esta batalha para entender e criar, como para qualquer outro leitor e escritor de literatura, as palavras vão remeter a emoções, memórias, ideias do tradutor em um intenso fluxo de consciência subjetiva. Não é uma operação no vácuo, nem tampouco um transplante de significado. Da mesma maneira que as palavras escolhidas pelo autor original têm ressonâncias que são apenas dele e as quais são importantes para a vida do texto, as palavras escolhidas pelo tradutor também têm fortes ressonâncias pessoais (BUSH, 2003, p. 1).
\end{abstract}

Como afirmado por Peter Bush, a subjetividade do autor se revela em suas escolhas no texto e, seguindo o mesmo argumento, uma vez que as palavras também exercem o mesmo efeito sobre o tradutor, torna-se impossível a sua invisibilidade. As palavras escolhidas revelam recantos de emoções, memórias e ideias de cada autor e de cada tradutor. Woodsworth afirma:

\begin{abstract}
A melhor analogia que encontro para descrever a estranha relação entre o tradutor e o autor é bem simples e se baseia na dificuldade que o indivíduo encontra em andar com outra pessoa, isto é, andar literalmente junto, não lado a lado, mas compondo uma única sombra. A tarefa do tradutor é aprender a ajustar-se ao passo, o ritmo da marcha, para adequar-se perfeitamente ao passo do autor. Não é uma questão de suprimir sua individualidade: haverá sempre duas pessoas andando (WOODSWORTH, 1988, p. 293).
\end{abstract}

O tradutor sempre estará presente no texto. Ainda que haja a ilusão da mesma sombra, são dois textos, dois autores. O que deve ser questionado é se autor e tradutor têm o mesmo 
poder simbólico em termos sociais. Na prática, podemos dizer que o tradutor exerce um poder concreto enorme, tendo em vista que os textos chegam às pessoas por meio de seu trabalho, os leitores partilham do capital cultural que ele adquiriu. De fato, acreditamos que a discussão em torno da visibilidade ou não do tradutor sequer ocorreria se desde sempre lhe fosse dado crédito pelo trabalho (isto é, que toda tradução trouxesse o nome do tradutor responsável) e direito à voz nos paratextos. Se os leitores tivessem conhecimento do que está por trás de algumas escolhas tradutórias, saberiam que não há esconderijo para o tradutor e que sua presença não deveria ser percebida apenas quando ele erra, mas por todos os acertos que fazem com que haja o intercâmbio de informações desde sempre entre povos cujas línguas tanto diferem. 


\section{REFERÊNCIAS BIBLIOGRÁFICAS}

ARROJO, Rosemary. A relação exemplar entre o autor e o revisor (e outros trabalhadores textuais semelhantes) e o mito de Babel: alguns comentários sobre História do Cerco de Jericó, de José Saramago. Delta, São Paulo, v. 19, n. especial, 2003. Disponível em: $<$ http://www.scielo.br/scielo.php?script=sci_arttext\&pid=S0102-44502003000300012 >. Acesso em: 02 jul. 2007.

BARTHES, Roland. A morte do autor. In: O rumor da língua. Tradução de Mário Laranjeira. São Paulo: Brasiliense, 1988.

BASSNETT, Susan. Estudos de tradução. Tradução de Vivina de Campos Figueiredo. Lisboa: Fundação Calouste Gulbenkian, 2003.

The meek or the mighty: reappraising the role of the translator. In: ÁLVAREZ, Román; ÁFRICA VIDAL, Carmen (Ed.). Translation, power and subsversion. Clevedon, Filadélfia/Adelaide: Multilingual Matters, 1996. p. 10-24.

BOURDIEU, Pierre. The field of cultural production: essays on Art and Literature. Columbia University Press, 1993.

As regras da arte: gênese e estrutura do campo literário. Tradução de Miguel Serras Pereira. Lisboa: Editorial Presença, 1996.

A distinção: crítica social do julgamento. Tradução de Daniela Kern e Guilherme J. F. Teixeira. Porto Alegre: Zouk, 2008.

Bertrand Brasil, 2009.

O poder simbólico. 12. ed. Tradução de Fernando Tomaz. Rio de Janeiro:

BURKE, Sean. The death and the return of the author: criticism and subjectivity in Barthes, Foucault and Derrida. $2^{\text {nd }}$ ed. Edimburgo: Edinburgh University Press, 1998.

BUSH, Peter. The translator as writer: the case of Juan Goytisolo's a cockeyed comed. Quaderns, revista de traducció, Barcelona, n. 10, 2003. Disponível em: <http://ddd.uab.cat/pub/quaderns/11385790n10p121.pdf>. Acesso em: 13 jun. 2007.

CERVANTES, Miguel de. O engenhoso cavaleiro D. Quixote de La Mancha.Tradução de Sérgio Molina. São Paulo: Editora 34, 2007.

CHARTIER, Roger. Escutar os mortos com os olhos. Tradução de Jean Briant. Estudos Avançados, São Paulo, v. 24, n. 69, p. 7-30, maio/ago. 2010.

COMELLAS, Pere. Autoria como tradução ou tradução como autoria: Milan Kundera, Jorge Luis Borges e o fim do indivíduo. Cadernos de Tradução, Santa Catarina, v. 2, n. 24, 2009. Disponível em: <http://www.periodicos.ufsc.br/index.php/traducao/article/view/13174>. Acesso em: 10 jul. 2010.

DU BELLAY, Joachim. Defesa e ilustração da língua francesa. Tradução de Philippe Humblé. In: FAVERI, Cláudia Borges; TORRES, Marie-Hélène Catherine (Org.). Clássicos da teoria da tradução. Florianópolis: Editora UFSC, 2004. p. 24-33.

DERRIDA, Jacques. Living on: border lines . In: HARTMAN, G. (Ed.). Deconstruction and criticism. Nova York: The Seabury Press, 1979. p. 75-176.

ESTEVES, Lenita R. Transparência ou opacidade: o que seria "politicamente correto" em tradução. Estudos Linguísticos - Anais de Seminários do GEL, Ribeirão Preto, v. 1, 1993. 
GOUANVIC, Jean-Marc. A Bourdieusian theory of translation, or the coincidence of practical instances field, "habitus", capital and "illusio". The Translator, v. 11, n. 2, p. 147166, 2005.

KUNDERA, Milan. Les testaments trahis. Paris: Gallimard, 1993.

A arte do romance. Tradução de Teresa Bulhões Carvalho da Fonseca.

São Paulo: Companhia das Letras, 2009.

MESCHONNIC, Henri. Poética do traduzir. Tradução de Jerusa Pires Ferreira e Suely Fenerich. São Paulo: Perspectiva, 2010.

PRUNC, Erich. Priests, princes and pariahs*: constructing the professional field of translation. WOLF, Michaela; FUKARI, Alexandra (Ed.). Constructing a sociology of translation. Amesterdam/Filadélfia: John Benjamins, 2007. p. 38-56.

REMNICK, David. The translation wars. The New Yorker, v. 81, p. 98, 7 Nov. 2005. Disponível em: <http://www.newyorker.com/archive/2005/11/07/051107 fa_fact_remnick>. Acesso em: 28 ago. 2009.

STEINER, George. Understanding as translation. After Babel: aspects of language and translation. $3^{\text {nd }}$ ed. London/New York: Oxford University Press, 1998.

VENUTI, L. The translator's invisibility: a history of translation. London: Routledge, 1995.

VIDAL CLARAMONTE, Carmen Africa. Re-presenting the "Real" Pierre Bourdieu and the legal translation. The Translator, v. 11, n. 2, p. 259-275, 2005.

WOLF, Michaela. Bourdieu's "rule of the game": an introspection into methodological questions of translation sociology. Matraga, Rio de Janeiro, v. 14, n. 20, 2007.

WOODSWORTH, Judith. Metaphor and theory: describing the translating process. In CHAFFEY, P., RYDNING; ULRIKSEN, S. (Ed.). Translation theory in Scandinavia. Proceeding from SSOTT III. Oslo: University of Oslo, 1988.

\footnotetext{
${ }^{1}$ What is translation? On a platter,

A poet's pale and glaring head,

A parrot's screech, a monkey's chatter,

And profanation of the dead.

The parasites you were so hard on,

Are pardoned if I have your pardon,

O Pushkin, for my stratagem.

I travelled down your secret stem,

And reached the root, and fed upon it;

Then, in a language newly learned,

I grew another stalk and turned,

Your stanza, patterned on a sonnet,

Into my honest roadside prose--,

All thorn, but cousin to your rose.

2 Tradução minha.
} 